\title{
Apply Student-Centered Learning on Computer Education
}

\author{
Yiqun Chen ${ }^{\mathrm{a}}$, Jian Yin ${ }^{\mathrm{b}}$ \\ ${ }^{a}$ Guangdong University of Education, Sun Yat-sen University, Guangzhou, China \\ ${ }^{b}$ Sun Yat-sen University, Guangzhou, China
}

\begin{abstract}
It has been long noticed that students are lacking the motivation for those type of teacher-centered learning environment. Student-Centered Learning (SCL) is used in the literature to indicate the shift of emphasis from the teacher to the student as the heart of the learning process. In this work we have discussed the methodology of SCL, presented our experience of applying SCL on computer education. Students play the active role in this process and take responsible for their own learning. Tutors are required to use new method to deliver knowledge, being a guider more than an expert.
\end{abstract}

Index Terms: Student-centered learning; computer education

(C) 2011 Published by MECS Publisher. Selection and/or peer review under responsibility of the International Conference on E-Business System and Education Technology

\section{Introduction}

The term student-centered learning (SCL) is widely used in the teaching and learning literature. In many traditional teaching contexts, it is a kind of teacher-centered learning environment. The teachers choose one content, look up the references, consider how to structure information, and then deliver the knowledge to the students. Students just sit there and accept all information from tutors, making notes, following the guidance from tutors without any selection or motivational thinking. It's a 'teacher directed' or 'teacher controlled' environment, which is not so good for the students to learn the knowledge and master the skill on how to learning. The teacher-focused/transmission of information formats, such as lecturing, have begun to be increasingly criticized and this has paved the way for a widespread growth of 'student-centered learning' as an alternative approach.

Student-centered learning is issued to improve the students' responsibility on their own learning, which will inspire their passion and achieved a better result. In Student-centered teaching context, students are accepted as they are, not as the tutor thinks they ought to be. It allows the difference exists among students, the tutor acknowledges that the students bring their feelings to the 'classroom' as well as their intellect and needs, tutors will design different content for different students. It involves the students to play an important part in the quality of the student's learning, affecting the student's motivation to learn and be responsible.

Computer science is a subject which is more about technology than artist. Practice is very important and it required the student to exercise what they learned in the class again and again. We always say "you try it, you

* Corresponding author.

E-mail address: ${ }^{\mathrm{a}}$ ChenYiqun@ gmail.com 
know it". Applying student-centered learning methodology on computer science education can involve the students to join the whole learning procedure. Students become passive, apathetic and bored; they can deeply understand why some technology is developed, for what kind of real application how and when they can be used. The greater involvement in the learning process the student achieved will enable them to learn from their own experience. This involves forming links between doing and thinking.

\section{Methodology of Student-centered learning}

The notion of learner-centered models in higher education has been around at least since the mid-1980s[1]. Colleen Carmean and Jeremy Haefner, 2002 EDUCAUSE National Learning Infrastructure Initiative(NLII) Fellows, provided an excellent synthesis of the various ways in which student-centered learning has been defined, calling it "deeper learning." Using five key principles, they maintained that a deeper learning experience occurs when learning is social, active, contextual, engaging and student-owned[2].

The main principles of student-centered learning are[3]:

- The learner has full responsibility for her/his learning

- Involvement and participation are necessary for learning

- The relationship between learners is more equal, promoting growth, development

- The teacher becomes a facilitator and resource person

- The learner experiences confluence in his education

- The learner sees himself/herself differently as a result of the learning experience

Student-centered learning is about a change in the traditional role of the tutor from an owner of knowledge to one who should think about the variety of ways in which students learn and endeavor to meet them. Studentcentered learning has a variety of features. The learner (student) has some choice about some or all of what, when and how she/he learns, the learner (student) takes some responsibility for their own learning, this being encouraged through the tutor's actions. Tutors should help students to discover their own learning styles, to understand their motivation and to acquire effective study skills that will be valuable throughout their lives. It's not easy to put this approach into practice, tutors need to help students to set achievable goals according to individual situation, encourage students to assess their own works and their performance, help them to work cooperatively in groups and ensure that they know how to exploit all the available resource for learning.

\section{How to apply student-centered learning on computer education}

The fundamental to student-centered learning is the idea of passing ownership of the course to the student. With ownership comes responsibility on the part of the student. For example, a student who owns a portfolio of work will have discussed and agreed its contents, added to it on his/her own accord, used it at interviews and generally cared about it. Pass the "ownership" to the student doesn't means that ask the students to do what tutors do in traditional teaching contexts. In student-centered learning, students need to be involved in the target setting procedure, also the assessment process; students must consider how they can demonstrate achievement of the course. Note that here, students are involved in a number of stages of decision making importantly.

To convey the student-centered learning in classroom, we adopt a number of strategies, which include

\section{A. involving students in decision making}

We encourage tutors to set the given course into the local context and provide 'real' materials for the student to choose. The intention therefore is to make the course more work-related, which can interest the students and engage students in an active way.

For example, when we work on the course "database concepts", we design a task, saying build a Website as interface for users to search data from some database. During the procedure, students are required to choose one

This work is supported by the Foundation for Innovative Graduate Training Program of Guangdong (09SFKC03), Foundation for Distinguished Young Talents in Higher Education of Guangdong(LYM09137). 
department in the school, visit the staff to learn about the querying requirement, and then design the interface by themselves. Further more, students are required to decide the following items together:

- 'what will be the deadline?'

- ' how to evaluate the works?'

- 'what function is required'.

\section{B. $\quad$ using small group work to encourage sharing of ideas and mutual support}

For every big topic or task, we organize students to build group by themselves. Everyone takes responsibility in the union. Group members should recognize that it is acceptable to express its' own feelings while respect the ideas and views of others, not always pursuing own ideas, and finally keep to agreement.

Sometimes, we lay the room out as a circle to encourage discussion and to reduce the focus of attention on the tutor, using a 'round' to allow students to say what they think and feel about something. It is particular useful for students to cooperate with each other.

Observers of student group interaction often find that students do not work productively, waste time, repeat old information, or become confrontational[4].That is because students' communication and group interaction habits are developed over two decades of formal education. These habits differ from student to student. Some may try to take control of the group, others may become passive, and still others will become overly verbose, while others will shy away from commenting. In some instances, they may find themselves in small groups that actually harm individuals and the learning climate. That's where tutors should do their job, to build a health and safety environment for individual and group learning.

\section{Build a health and safety environment}

To encourage the students enjoying the ownership, to make student-centered learning really work established, we try to build a health and safety environment.

First of all, we value mistakes as an opportunity to learn, tutors should be non-judgmental, avoid using "You ought .....", "You should ....." as they do not encourage independence from the tutor, we use "you could ..." as replacement.

Secondly, the use of language affects the growth of responsibility, we try to use encourage language than traditional command language. We change 'can't' to 'won't', "I can't tell you this" becomes "I won't tell you this", and change 'but' to 'and', and owning tutors own feelings: "You really annoy me" become "I find you really annoying"... the approaches of expressing are not easy to achieve, but the gains are worth the hard work.

Thirdly, between students, we some ground rules with the group, and try to help every student follow them, for example:

- listening to others and not always pursuing own ideas

- respecting the ideas and views of others

- $\quad$ keeping to agreements

- avoiding physical and mental abuse such as sarcasm

- recognizing that it is acceptable to express your feelings

In traditional computer science education, it has been common to divide the theoretical aspects of a course from its practical application. This division has often had an effect on the teaching methods used, with the theory tutors imparting knowledge through a lecture or lesson, and the practical tutor demonstrating a technique or process and supervising the subsequent practice. Actually, such division required the students to makes the link between theory and practice by themselves. We try to combine the theoretical and practical class together, let the students try the technology related to the theory they just learned directly, which can give them a more deeply understanding and experience of the theory.

We try to let students learn from experience. If learning is to arise from experience then reflection is needed. After practice, the resulting feelings and thoughts enable new or modified generalizations (or concepts) to be 
formed. After that, the new concepts will be introduced, in turn; it must then be tested out in new situations. Students are guided to plan for the next activities, carry it out and then reflect on it, relating what happens back to the theory. Note that experience is used to test out ideas and assumptions rather than to passively obtain practice. During this procedure, tutors have an important role in devising appropriate experiences and facilitating reflection. As we emphasize on student-centered learning, we should allows the difference exists among students. We support the students to bring their feelings to the 'classroom' as well as their intellect and needs by giving them individual feedback. So we bring out a good working feedback system as the following.

\section{Build a good working feedback system}

To apply student-centered learning well, both in the class and outside, we must consider how much a teacher can facilitate vs. direct. Teachers wishing to ensure a student-centered approach must know their students and their backgrounds in order to help them develop appropriately. During the procedure, when student take responsible on their own learning and start to use available material to do their job, they need the continue guidance from tutors. When they finish their job, it's quite important to evaluate every student's job and help them to draw out the experience, which will take an important role in their continue studying. Clearly there are cultural and personal issues to be addressed, as student-centered learning will be different for each group. We work out a feedback system for the student-centered learning class. Tutors should provide opportunities for students to investigate and debate findings and to reflect on actions and experiences. Every tutor is required to give feedback for every task delivered in the class for every student. Students can improve their works according to the individual feedback.

Feedback can be delivered in several ways. It may be made in the documents the students handed in. It can also be made in blog. For example, for some course assignments I directed students to content-specific Web sites on which they researched a topic. Also design some assessment modules, such as strategic planning and request for proposals. After integrating this research with their own ideas and solutions, students published their work including the assessment modules, assignment requirements on their blogs. Blog visitors, including tutors and other classmates, can interact by exchanging ideas and asking questions of each other. The guest practitioners also commented on student blog entries. Given that many online students miss the face-to-face contact realized in a traditional classroom, blogging offers particularly useful opportunities for learner-centered feedback and dialogue.

\section{Conclusion}

Teacher-centered learning has the teacher at its centre in an active role while students in a passive, receptive role. Student-centered learning putting students first requires tutors to change their traditional teaching method, focuses on the student's needs, abilities, interests, and learning styles, and pay more attention to make students to be active, responsible participants in their own learning. That is in stark contrast to existing establishment/teacher-centered lecturing and careerism. Student-centered learning is with the teacher as a facilitator of learning. This classroom teaching method acknowledges student voice as central to the learning experience for every learner. It is obvious that it needs a significant amount of efforts to convince people to try a new approach. Being challenged with the required transition from teacher-centered, lecture-based teaching to student centered, and technology-based learning, today's educational reforms call for successful technology supported teacher education programs.

One of the first points to emphasis is learning as opposed to teaching. Think about how we all learn and the very fact that individuals all have slightly different preferred approaches to learning, or learning styles. We apply student-centered learning on computer education by building an health and safety environment for involving student during decision making, using small group work to encourage sharing of ideas and mutual support, combining the theoretical and practical class together and building a good working feedback system. The hard work try to keeping students mentally, and often physically, active in their learning through activities that involve them in gathering information, thinking, and problem solving.

The goal of our work is equipping individuals with knowledge, understanding and skills for success in their future employment in the computing industry, providing opportunities for learners to develop a range of skills and techniques and attributes essential for successful performance in studying and working life, enabling further 
professional qualification in computing or a related area. It's not easy to apply student-centered learning in practice, but the goal deserves the hard work.

\section{References}

[1] M.D.Svinicki, "New Directions in learning and Motivation," in Teaching and Learning on the Edge of the Millennium: Building on What We Have Learned, M.D.Svinicki, ed.(San Francisco:JosseyBass, 1999),pp.13-16.

[2] Bob Bender, "Student-Centered Learning: A Personal Journal" Educause Center for Applied Research Research Bulletin. Volume 2003, Issue 11.

[3] Brenda Hall ."Student-Centred

Learning". http://www.eslschool.com/archives/2006/07/studentcentred_learning.php

[4] Stinson, JE \& Milter, RG 1996. Problem-based learning in business education. In Wilkerson, L \& Gijselaers, WH (eds). Bringing Problem-Based learning in Higher Education: Theory and Practice. San Francisco: Jossey-Bass 